OPEN ACCESS

Edited by:

Ángel J. Gallego,

Universitat Autònoma de Barcelona

Spain

Reviewed by:

Ivan Ortega-Santos,

University of Memphis, United States

Ekaterina Chernova,

Universitat Autònoma de Barcelona,

Spain

*Correspondence:

Leticia Pablos

I.pablos.robles@hum.leidenuniv.nl

Specialty section: This article was submitted to

Language Sciences,

a section of the journal

Frontiers in Psychology

Received: 31 August 2017 Accepted: 11 December 2017

Published: 11 January 2018

Citation:

Pablos L, Doetjes J and Cheng LL-S (2018) Backward Dependencies and in-Situ wh-Questions as Test Cases on How to Approach Experimental Linguistics Research That Pursues

Theoretical Linguistics Questions.

Front. Psychol. 8:2237.

doi: 10.3389/fpsyg.2017.02237

\section{Backward Dependencies and in-Situ wh-Questions as Test Cases on How to Approach Experimental Linguistics Research That Pursues Theoretical Linguistics Questions}

\author{
Leticia Pablos $^{1,2 *}$, Jenny Doetjes ${ }^{1}$ and Lisa L.-S. Cheng ${ }^{1,2}$ \\ ${ }^{1}$ Leiden University Centre for Linguistics, Leiden University, Leiden, Netherlands, ${ }^{2}$ Leiden Institute for Brain and Cognition, \\ Leiden University, Leiden, Netherlands
}

The empirical study of language is a young field in contemporary linguistics. This being the case, and following a natural development process, the field is currently at a stage where different research methods and experimental approaches are being put into question in terms of their validity. Without pretending to provide an answer with respect to the best way to conduct linguistics related experimental research, in this article we aim at examining the process that researchers follow in the design and implementation of experimental linguistics research with a goal to validate specific theoretical linguistic analyses. First, we discuss the general challenges that experimental work faces in finding a compromise between addressing theoretically relevant questions and being able to implement these questions in a specific controlled experimental paradigm. We discuss the Granularity Mismatch Problem (Poeppel and Embick, 2005) which addresses the challenges that research that is trying to bridge the representations and computations of language and their psycholinguistic/neurolinguistic evidence faces, and the basic assumptions that interdisciplinary research needs to consider due to the different conceptual granularity of the objects under study. To illustrate the practical implications of the points addressed, we compare two approaches to perform linguistic experimental research by reviewing a number of our own studies strongly grounded on theoretically informed questions. First, we show how linguistic phenomena similar at a conceptual level can be tested within the same language using measurement of event-related potentials (ERP) by discussing results from two ERP experiments on the processing of long-distance backward dependencies that involve coreference and negative polarity items respectively in Dutch. Second, we examine how the same linguistic phenomenon can be tested in different languages using reading time measures by discussing the outcome of four self-paced reading experiments on the processing of in-situ wh-questions in Mandarin Chinese and French. Finally, we review the implications 
that our findings have for the specific theoretical linguistics questions that we originally aimed to address. We conclude with an overview of the general insights that can be gained from the role of structural hierarchy and grammatical constraints in processing and the existing limitations on the generalization of results.

Keywords: backward dependencies, in-situ wh-questions, coreference, negative polarity items, event-related potentials, self-paced reading, parsing, grammatical constraints

\section{INTRODUCTION}

The study of language from an experimental point of view is a relatively young field in linguistics. In particular, work connected to the parsing or on-line comprehension of sentences-our area of interest in the present research-dates back to the late 60's and early 70's and has evolved from the work of various researchers who tried to put some of Chomsky's (1965) seminal ideas to test (e.g., Bever, 1970; Levelt, 1970; Kimball, 1973; Fodor et al., 1974; among others). Leaving the origins of the field aside (see Townsend and Bever, 2001; Phillips, 2013, for an overview), in this article we discuss the approach that researchers addressing topics based on strong theoretical linguistics background have taken to conduct experimental research that provides evidence for the validity of specific theoretical questions in linguistics or for the adequacy of general properties of language, such as structural hierarchy, or dependencies.

We first discuss the challenges this type of experimental approach faces in finding a balance between addressing theoretically relevant questions and being able to implement these questions in a controlled and realistic experimental paradigm. Secondly, we discuss the fact that certain theoretical questions can only be approached after building upon the evidence provided by a series of consecutive previous studies. Several researchers in the field have targeted a specific linguistic question starting from a seemingly simple paradigm in order to build upon the results and create more linguistically complex testing scenarios over thematically related follow-up experiments. Third, we illustrate through our own work two possible ways to carry out linguistic experimental research that bears heavily on linguistic theory. On the one hand, we examine linguistic phenomena that are similar at the conceptual level but different in their specific instantiations by investigating long-distance dependencies that involve either coreference of a cataphoric pronoun, or the backward interpretation of a negative polarity item in Dutch. These two linguistic phenomena have in common that the licensee always precedes its licensor and that the cue for how to identify a licensor rests upon the hierarchical structure. Specifically, we test how the expectation for the upcoming licensor might be impacted differently by linear and structural distance. For this, we discuss two experiments by Pablos et al. (2015, submitted) using event-related potentials (ERPs). On the other hand, we examine processing of a single linguistic phenomenon in unrelated languages. Specifically, we test the on-line processing of wh-in-situ questions in Mandarin Chinese and French. Current theoretical approaches all posit a dependency between the left periphery (e.g., in CP) and the in-situ wh-phrase, regardless of whether the dependency is established through covert movement of the wh-phrase to the left periphery or binding of the wh-phrase by a questionoperator (for an overview, see Cheng, 2009; Bayer and Cheng, 2017). In processing terms, the parser does not encounter an overt cue to determine the interrogative or declarative nature of the upcoming structure until the wh-phrase position. At the wh-phrase position, the parser might need to backtrack to the left periphery to establish a dependency in order to interpret the $w h$-word. In relation to this second phenomenon, we discuss four self-paced reading experiments by Pablos et al. (submitted). Throughout the presentation of these two cases, we discuss the potential cost of simplifying a theoretically-based research question so that the empirical research can still lead to a meaningful contribution to linguistic theory. In particular, in the section Studies on the neural architecture of language we discuss how the research question can evolve from its starting point to its end point so that it becomes an empirically testable question.

\section{Challenges for Theoretically Informed Experimental Research in Linguistics}

In general, theoretical models are posited to represent the relationships, rules, constraints, etc., that relate different linguistic entities and structures. These theoretical models tend to rely mostly on evidence coming from speakers' judgment data and from corpus data. As it will be discussed in the section Studies on the neural architecture of language, there is an ongoing debate about whether the processing of language possesses mental representations that can be directly mapped to existing theoretical models (for further discussion see Phillips et al., 2011; Lewis and Phillips, 2015; Kush et al., 2017; Parker and Phillips, 2017; among others). Based on the assumption that this mapping exists, there is a growing amount of experimental work that evaluates if existing theoretical models can be corroborated and put to test.

One of the first challenges for this type of experimental approach is finding a compromise between addressing a theoretically relevant question and being able to implement the question at hand in a controlled experimental paradigm that leads to interpretable data and credible evidence. As this approach is driven by a theoretical linguistic question, the process starts by carefully thinking of an appropriate experimental setup that can target the question in the best possible way. The choice of methodology is also dependent on the theoretical question, which means that more than one method can be considered initially. There is a core difficulty about proceeding in this manner: the simplification of the linguistic paradigm linked to the research question. In this simplification process, attention has to be paid to 
two things: the first is to test with limited variables in the interest of interpretable results, and the second is the permanence of the core theoretical question to the extent that is still relevant to the discussion in the field.

Consider the licensing contexts of Negative Polarity Items ${ }^{1}$ (NPIs) as an example of a hypothetical testing scenario where the main research question is to find real-time or brain signatures of different NPI licensing environments. We know from existing theoretical linguistics research that NPIs can be licensed in different types of syntactic-semantic environments (e.g., conditionals, questions, comparatives, negative structures, see Giannakidou, 2011 for a full description). Thus, if there is some correspondence between the competence that speakers have of the different NPI licensing contexts and the speakers' use of this knowledge in real-time, a possible research question that we could put forth is whether these different syntactic-semantic environments yield different processing effects or whether these effects can be unified in that, if tested, they could all result into similar brain or psycholinguistic/algorithmic signatures. However, there is one constraint, namely, it is quite challenging to test all possible licensing contexts in one go. Further, if we test all possible contexts with one single experiment, we might get un-interpretable data from the fact that there are too many factors at play that are difficult to control experimentally. We therefore might break the question down into first testing only those contexts where there is an overt licensor (such as negation) that precedes the NPI. This reduces the number of factors and allows for a more uniform set of experimental stimuli, in the sense that we can at least identify the impact of an overt licensor in the processing of NPI (sentences) online. Once there is enough experimental evidence coming from testing environments with an overt licensor and some consensus has been reached on how NPI licensing works online (e.g., similar brain or psycholinguistic signatures are elicited), more contexts can be introduced in the experimental repertoire and in future experimental research examining the real-time signatures of NPI licensing. Nevertheless, this will only be possible when effects due to the NPI not being licensed, for example, have been robustly replicated intra-linguistically and possibly using different experimental methods. If we turn to the research on NPI processing of approximately the last 20 years, we can see that this is precisely how researchers working on this particular research question have approached this problem. Work by Shao and Neville (1998), Saddy et al. (2004), Drenhaus et al. (2005), Vasishth et al. (2008), Xiang et al. (2009), Yurchenko et al. (2013), and Parker and Phillips (2016), just to name a few, has examined the processing of NPIs by first looking at very basic paradigms where the licensor (i.e., negation) was either absent or in an inaccessible position. From all the existing research, to our knowledge, only Drenhaus et al. (2007), Steinhauer et al. (2010) and Xiang et al. (2016) examined other licensing environments

\footnotetext{
${ }^{1}$ Negative polarity items are items such as anything in English, which must appear under certain licensors, such as negation, as we can see from the comparison between (ia) and (ib):

(i) a. John didn't buy anything.

b. *John bought anything.
}

that did not require an overt licensor (i.e., wh-questions in Drenhaus et al., 2007; non-veridical contexts in Steinhauer et al., 2010; and emotive predicates in Xiang et al. 2016).

Furthermore, the existing studies illustrate a lack of broad cross-linguistic research in that, except for a few studies that have examined the incremental interpretation of NPI licensing in languages such as Basque (Pablos and Saddy, 2009; Pablos et al., 2011), Mandarin Chinese (Tsai et al., 2013), Dutch (Yurchenko et al., 2013), Italian (Vespignani et al., 2009), Spanish (Pablos, 2009), and Turkish (Yanilmaz and Drury, 2013), most of the existing psycholinguistic generalizations have been made based on experimental evidence coming mainly from languages such as English and German. Further, the on-line methods used vary from the use of ERPs, to eye-tracking, self-paced reading and speeded acceptability judgments, and the questions they targeted varied in nature. In all of the studies, the resulting effect reflects an increase of mental processing effort or an interference effect in retrieving an element from memory, but the observable is different depending on the method, and cannot be univocally linked to a particular neurological/psychological process (see discussion of Poeppel and Embick's, 2005, Granularity Mismatch Problem in the section Studies on the neural architecture of language). Therefore, only a few generalizations can be made based on the existing experimental evidence and these generalizations come mainly from research that has examined illusory licensing effects in NPI licensing contexts (see Parker and Phillips, 2016 for an overview of these effects in the psycho/neurolinguistics literature).

\section{Studies on the Neural Architecture of Language}

One of the recurrent questions in the current psycholinguistic and neurolinguistic literature is whether researchers assume a correspondence between grammar (or our language competence system) and the parser (or our language performance system). Under the assumption of this correspondence, these two systems are able to feed each other and are part of the same cognitive system. Without such correspondence, the two systems are assumed to work separately and to abide by different rules or processes (see Lewis and Phillips, 2015 for further discussion). The research discussed here assumes that we have one cognitive system that is in charge of handling both competence and performance. What researchers working in the field of cognitive neuroscience of language have tried to address is the need to find a compromise between the theoretical assumptions that linguists take for granted and how these assumptions might be concretely realized in neurological terms (or signatures) and how they should be interpreted (see Marantz, 2005, 2013; Poeppel and Embick, 2005; Poeppel, 2012; Poeppel et al., 2012; Embick and Poeppel, 2015). Embick and Poeppel (2015, p. 358) describe one by one the challenges of how to test in an integrated way "theories of the (psycho)linguistic type that make claims about the computations and representations that constitute grammar and aspects of language use (referred to as "Computational-Representational" (CR) Theories)" in relation to "theories that study the structure and function of the brain 
coming from the Neurobiology of Language (NB) and that are more implementational in character." Further, they discuss how CR-type of theories are currently more fine-grained than the current theories on how the linguistic representations and computations are realized in the brain (NB-theories). Under Poeppel and Embick's (2005, p. 104) and Embick and Poeppel's (2015, p. 361) view, what makes the unification of these two theories challenging is the Granularity Mismatch Problem (GMP), which refers to the fact that linguistic and neurolinguistic studies of language operate with objects of different "conceptual granularity." Linguistic computation involves a number of fine-grained distinctions and explicit computational operations, whereas neuroscientific approaches involve broader conceptual distinctions. In their words, "this mismatch prevents the formulation of theoretically motivated, biologically grounded, and computationally explicit linking hypotheses that bridge neuroscience and linguistics" Poeppel and Embick (2005, p. 104) and it makes it "difficult to establish CR/NB linking hypotheses because in general the study of how the brain computes what it computes in language is at present too coarse to link up meaningfully with the distinctions made on the CR side" (Embick and Poeppel, 2015, p. 59). Adopting the view that the development of CR theory is an essential step toward understanding NB, Embick and Poeppel (2015, pp. 360-361) suggest three different ways in which CR and NB could interplay. The first is Correlational Neurolinguistics, where CR theories of language are used to investigate the NB foundations of language and in which knowledge of how the brain computes is gained by capitalizing on CR knowledge of language. This, for instance is the type of approach that works linking theoretical and psycholinguistic work have followed (see the work by Phillips and Lau, 2004; Lewis and Phillips, 2015, for example). The second way is Integrated Neurolinguistics, where Correlational Neurolinguistics plus the NB perspective provide crucial evidence that arbitrates among different CR theories. In Integrated Neurolinguistics, it is the brain data that enriches our understanding of language at the CR-level, for example. Third and last, Embick and Poeppel (2015) suggest that there is an Explanatory Neurolinguistics way where, besides Correlational and Integrated Neurolinguistics, something about NB structure or function explains why the CR theory of language involves particular computations and representations but not others.

Research over the past 10 years on the neural signatures of language has looked for experimental evidence that could show the process of how the building up of minimal units (which ranged from constituents, to minimal phrases to morphemes) occurs in the on-line computation of language, and that could show one of the basic intrinsic properties that characterizes the language faculty, namely, hierarchical structure. Within this field of work, we can distinguish three different groups of studies: (i) those that looked at whether there is hierarchy at the sentential level and whether this can be captured in terms of brain-oscillations or specific activations in syntax-semantics related brain areas (e.g., ERP studies by Luo and Poeppel, 2007; Arnal et al., 2015; Ding et al., 2015; Nelson et al., 2017; fMRI studies by Pallier et al., 2011; Brennan et al., 2012); (ii) those that examined whether a hierarchy can be found at the word level by using either fMRI or MEG methods (e.g., Fruchter and Marantz, 2015; Fruchter et al., 2015) and (iii) those that examined the compositionality of incremental meaning using MEG methodology (e.g., Bemis and Pylkkänen, 2011; Pylkkänen et al., 2011).

The evidence coming from the first set of studies suggests that we build sentences in small constituents as we parse them incrementally and that our brain makes clear distinctions between random word lists and sentences with different constituent length, either in a more constrained (or custom made) traditional experimental setting, or in a more natural one (e.g., Brennan et al., 2012). The evidence from the second set of studies suggests that we are aware of the constituency within words in that they show differences between morphemes that hierarchically depend on the root of the word vs. those that do not. Finally, the third set of studies provides support for the construction of semantic composition starting from minimal linguistic phrases such as red boat and comparing them with non-compositional contexts such as a word list, e.g., cup, boat.

Even though the above studies have looked at different linguistic phenomena, they all seem to point to the building up of minimal linguistic units in the brain, whether we are examining minimal linguistic units at a word, phrase or sentence level. Through the use of different methods and from evidence coming from either brain oscillations or specific brain area activations, these studies have shown that there is a way to capture the representation of constituent structure in the brain. Further, all these studies have started from very simple experimental paradigms where they examined the most minimal possible linguistic interaction and they built upon their own previous results to get to robust evidence that can lead to potential generalizations about the neurobiology of language.

\section{Current Test Cases: Two Ways to Conduct Strongly Theoretically Informed Experimental Studies}

To illustrate some of the points made above, we discuss two ways in which we approach theoretical questions in experimental terms. The first way concerns the processing of two different linguistic phenomena, coreference and negative polarity item licensing, that are conceptually similar. Both coreference and negative polarity licensing can involve long-distance backward dependencies, where the licensee or dependent element occurs linearly before its licensor (although this configuration is not necessary for any of the two phenomena). Theoretical studies treat backward dependencies the same way as forward dependencies as structural hierarchy is the only important factor rather than linear precedence. The reasoning behind both ERP experiments is to examine if the strategies employed by the parser in the online interpretation of these two types of backward dependencies are similar, despite the different nature of the relation between the dependent element and its licensor. Even though the exact nature of the dependencies is different, both dependencies are restricted by syntactic structure. In other words, in both types of dependencies, there are positions in which the licensor can occur and positions from which it is impossible to enter into a licensing relation with the licensee. The question with respect to parsing is whether these structural restrictions are 
taken into account during an on-line parsing task, and whether the two types of dependencies are similar in this respect. These two types of dependencies were tested in the same language, Dutch, using the same methodology (ERPs).

The second way concerns the processing of the same linguistic phenomena, wh-in-situ questions, in languages with two different question formation strategies. French has both $w h$-fronting and in-situ wh-question strategies and Mandarin Chinese only has the in-situ wh-question strategy. The reasoning behind the four self-paced reading experiments we discuss is two-fold. First, as discussed above, we aim to examine the lack of an overt cue for a dependency with the left periphery (either through movement or through binding by a question-operator), and whether the encountering of the in-situ wh-phrase leads to backtracking in order to interpret the in-situ wh-phrase. Further, we examine whether the parser adopts different parsing strategies depending on whether the language only has one single whquestion formation strategy (e.g., only in-situ in Mandarin), or two strategies (as in French). If the strategies employed by the parser in the on-line interpretation of wh-in-situ questions in these two languages are alike, we can claim that there is a universal heuristics for interpreting in-situ questions in realtime. On the other hand, if the strategies differ between the two languages, we must conclude that they depend on the question formation strategies that are available to native speakers. From a theoretical point of view, it is expected that regardless of the question formation options that each language contains, insitu wh-questions should be parsed similarly, namely, they need to establish dependency in the left periphery. This hypothesis considers the scenario where the grammar and the parser proceed hand-in-hand. The alternative would be an approach that shows an asymmetry between what is expected by theoretical linguistics research and what the real-time evidence shows, where the predictions for the performance side of language would be based on experience or usage-based information. If results come up differently for the two languages, it would mean that the existence of more than one question formation strategy in a language might impact the process of interpreting in-situ wh-questions in real-time differently. In order to address these questions, and assuming that the grammar and the parser might be unified, we tested whether $w h$-in-situ questions are processed inherently slower than their declarative counterparts when there is no prosody or context helping the online interpretation of $w h$-in-situ questions in these languages. This is the result that the theoretical approaches will predict.

\section{TEST CASE 1: EVENT-RELATED POTENTIAL EXPERIMENTS ON BACKWARD DEPENDENCIES IN DUTCH}

\section{Cataphoric Pronoun Dependencies: Search for Antecedents Only in Grammatically Licit Positions}

The ERP experiment in Pablos et al. (2015) examined the processing of a backward dependency involving cataphoric pronouns, i.e., pronouns that linearly precede their antecedent. The restriction of pronominal reference can be captured under the principles of the Binding Theory (Chomsky, 1981) that indicates the configurations in which nominal elements can or cannot establish a coreferential relation. There are three Binding Principles, each of which concerns a different type of nominal element. Principle C restricts the distribution of Referential Expressions, including proper names such as Mary. This Binding Principle prohibits a Referential Expression (e.g., proper name) from being bound (Chomsky, 1981). We tested if the Binding Principle C constrains the on-line comprehension of pronounantecedent dependencies; in particular, whether antecedents are only interpreted in relation to the preceding pronoun in grammatically licit contexts (i.e., where no grammatical constraint is violated), as in the interpretation of Mary in relation to the cataphoric possessive pronoun her in (1). This scenario can be contrasted with a scenario in which establishing the antecedent-pronoun relation violates the Binding Principle C, as in (2). In such a case, the antecedent Mary and the pronoun she cannot be interpreted as referring to the same person in (2).

(1) $\mathbf{H e r}_{j}$ sister could not drive the car in Moscow while Mary was visiting.

(2) She $_{\mathrm{i} / *_{\mathrm{j}}}$ could not drive the car in Moscow while Mary was visiting.

In order to examine whether a grammatical constraint such as Binding Principle C is applied online in (2) and not in (1) at the proper name Mary, the well-attested Gender Mismatch Effect (GMME) paradigm was used (e.g., Sturt, 2003; van Gompel and Liversedge, 2003; Kazanina et al., 2007; Yoshida et al., 2014). In this paradigm, the gender mismatch effect at the antecedent position Mary with respect to his in (3) provides evidence that the parser has tried to interpret the pronoun at the antecedent position in this context. The GMME effect is observed in behavioral studies in that longer reading times in the mismatch condition in (3) than in the match condition in (1) are obtained. Conversely, when the antecedent position in (4) is compared to (2), no reading time difference is detected since Mary is barred as an antecedent due to Binding Principle C.

(3) His $_{\mathrm{k}}$ sister could not drive the car in Moscow while Mary was visiting.

(4) $\mathbf{H e}_{\mathrm{i}}$ could not drive the car in Moscow while Mary $\mathbf{j}_{\mathrm{j}}$ was visiting.

Previous studies have tested these specific pronoun-antecedent configurations in English and they measured reading times via different behavioral methods (i.e., self-paced reading and eyetracking). The ERP study by Pablos et al. (2015) that we discuss here examined what the neural reflections of the GMME were ${ }^{2}$ and whether the GMME could be cross-linguistically attested.

\footnotetext{
${ }^{2}$ At the time, there existed some ERP studies on the processing of forward (antecedent-)pronoun configurations (see Osterhout and Mobley, 1995; Van Berkum et al., 2007; Xu et al., 2013), but little evidence existed about how backward pronoun dependencies were processed in ERP terms. Studies on forward pronoun dependencies have resulted in the generation of a $\mathrm{P} 600$ at the mismatched pronoun she in contrast to the matched pronoun he in configurations such as the one in (i) from Osterhout and Mobley (1995).

(i) The uncle hoped that he/she had picked a good wine.
} 


\section{Paradigm Selection and Materials' Design}

Following the self-paced reading study by Kazanina et al. (2007), Pablos et al. (2015) created four different experimental conditions in Dutch to test the sensitivity of the parser to Principle C. As in (1) and (3), two "no-constraint conditions" where the pronoun could be linked to the antecedent were introduced. This is shown in the sentences in (5) and (6), which contain a possessive pronoun that either matches (haar female) or mismatches (zijn - male) the linearly first antecedent Suzanne . $^{3}$.

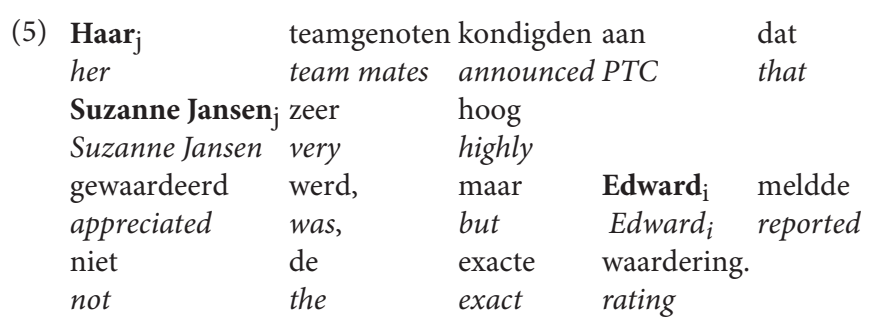

'Her teammates announced that Suzanne Jansen was highly appreciated, but Edward did not report the exact rating.'

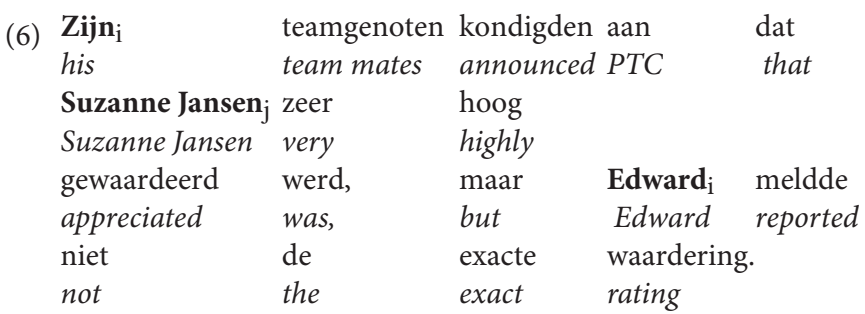

'His teammates announced that Suzanne Jansen was highly appreciated, but Edward did not report the exact rating.'

The other two experimental conditions were labeled as "Principle C conditions" and contained a cataphoric nominative pronoun in feminine [zij in (7)] or masculine [hij in (8)] form. Due to Principle C, these pronouns cannot corefer with the antecedent Suzanne in the embedded clause.

(7) $\mathbf{Z i j}_{\mathrm{i}}$ kondigde aan dat Suzanne Jansen , $_{\mathrm{j}}$ zeer hoog she announced PTC that Suzanne Jansen very highly gewaardeerd werd, appreciated was

maar Monika $\mathrm{a}_{\mathrm{i}}$ meldde niet de exacte waardering. but Monika reported not the exact rating

'She announced that Suzanne Jansen was highly appreciated, but Monika did not report the exact rating.'

\footnotetext{
${ }^{3}$ The indexing of (5) indicates the intended reading and abstracts away from the possibility that the pronoun haar "her" has a referent that is not mentioned in the sentence. This is also a possibility, in particular when the sentence is embedded in a context in which the referent has already been mentioned. In the experiment, the examples were given to the participants without further context. Our results, and the results of Kazanina et al. (2007) show that the parser starts an active search for a referent within the sentence after the pronoun is encountered.
}

(8) Hij $_{\mathrm{i}}$ kondigde aan dat Suzanne Jansen $\mathrm{j}_{\mathrm{j}}$ zeer hoog he announced PTC that Suzanne Jansen very highly gewaardeerd werd, appreciated was,

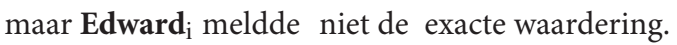
but Edward reported not the exact rating

'He announced that Suzanne Jansen was highly appreciated, but Edward did not report the exact rating.'

\section{Results and Discussion}

Pablos et al. (2015) found a significant ERP amplitude difference between the no-constraint conditions in (5) and (6) at the position of the name Suzanne in the antecedent Suzanne Jansen. This difference appeared as an anterior negativity over the 300-420 ms time window, where the no-constraint mismatch condition in (6) was more negative than the no-constraint match condition in (5) at the antecedent position. Furthermore, no difference was observed in the ERP waveforms between the Principle C constrained conditions in (7) and (8).

The results from this ERP experiment on Dutch backward pronoun dependencies show that the gender mismatch results in an anterior negativity and that, unlike in forward pronoun dependencies, there is no elicitation of a $\mathrm{P} 600^{4}$. The anterior negativity is interpreted to be connected to failure of meeting the expectation to find an antecedent that matches in gender with the pronoun at the antecedent position. The main conclusion that one can draw from the results is that the parser is sensitive to gender mismatch effects only when they occur in grammatically licit positions. The fact that this effect is not present in the Principle $\mathrm{C}$ conditions means that the parser respects structural constraints when interpreting sentences in an incremental manner.

\section{Backward Negative Polarity Item (NPI) Dependencies: Search for Licensors Only in Grammatically Licit Positions}

Similar to the cataphoric pronoun experiment discussed in the section Cataphoric pronoun dependencies, a second ERP study (Pablos et al. submitted) tested the processing of another backward dependency, a dependency involving negative polarity items. In this experiment, the Dutch negative polarity item ook maar iets "anything" occurs linearly before its licensor niet "not." Consider first a situation where the licenser precedes the licensee as in (9a), and compare it with a context where the NPI appears linearly before the licensor, similar to the cataphoric pronoun dependency case, as in (9b) (where the NPI appears in a sentential subject). As discussed by Hoekstra (1991) and Hoeksema (2000), the subordinate clause Dat het meisje ook maar iets geleerd heeft

\footnotetext{
${ }^{4}$ The P600 is an Event-related component with positive polarity whose onset usually occurs around $500-600 \mathrm{~ms}$ and which peaks around $600 \mathrm{~ms}$. Its topographical distribution is strongest over centro-parietal electrodes. It is a component that is generally elicited by syntactic violations, and its amplitude reflects the degree of difficulty of syntactic integration or reanalysis in parsing (see Osterhout and Holcomb, 1992; Hagoort et al., 1993; Kaan et al., 2000; Friederici et al., 2001, among others). The reader is referred to the discussion in Pablos et al. (2015) for the potential reasons for the lack of a P600 in the gender mismatch comparison in (5) and (6) at the antecedent.
} 
"that the girl has learned anything" in (9b) is within the scope of the matrix negation niet "not," meaning that structurally it is in a position where the NPI can be licensed by negation ${ }^{5}$. This is not the case with the negation niet "not" in the subordinate clause in (9c), where the NPI ook maar iets "anything" has scope over the negation. In this case the negation is in a position that is too low to act as a licensor of the NPI.

(9) a. Het is niet waarschijnlijk dat het meisje ook maar iets it is not probable that the girl anything
geleerd heeft.
learned has

'It is not probable that the girl has learned anything.'

b. [Dat het meisje ook maar iets geleerd heeft] is niet that the girl anything learned has is not waarschijnlijk. probable

'That the girl has learned anything is not probable.'

c. *[Dat het meisje ook maar iets niet geleerd heeft] is that the girl anything not learned has is waarschijnlijk. probable

Intended: 'That the girl has not learned anything is probable.'

The central question of this experiment was again if the parser respects grammatical constraints which would be apparent if the parser is sensitive to the hierarchical position of the licensor. The condition of "backward" NPI such as (9b) is an excellent condition to test this as we do not expect any licensor within the sentence subject, i.e., the dat "that"-clause, as shown in (9c). Furthermore, if we assume an incremental interpretation of the sentence in (9b), the only overt cue that the parser encounters linearly to determine that there cannot be a licensor for the NPI within the subordinate clause is the complementizer dat "that" and this should be enough to determine that the licensor can only occur in the main clause. The idea was that if we increase the linear distance at positions in the sentence where the parser does not expect a licensor [i.e., any position after the NPI within the dat "that"-clause, indicated by [A] in (10)], it should be less costly to integrate the upcoming material incrementally than if we increase the linear distance at positions in the sentence where the licensor is highly expected [i.e., any position after the main clause verb "to be," indicated by [B] in (10)].

(10) [Dat het meisje ook maar iets [A] geleerd heeft] is

that the girl anything learned has is
$[\mathrm{B}]$ niet waarschijnlijk.
not probable
'It is not probable that the girl has learned anything.'

\footnotetext{
${ }^{5}$ According to Hoekstra (1991) and Hoeksema (2000, p. 25), fronting a clause with a NPI in it yields grammatical results. Both argue that this is due to reconstruction at Logical Form, which places clauses back in their original positions. This further allows the complement-clause in (9a) to be within the scope of the matrix negator niet "not." Following their account, in this study, we assume that the NPI under examination is within the scope of the matrix clause negation and thus licensed by it.
}

We define the processing cost following the basic assumptions of the Dependency Locality Theory (DLT) proposed by Gibson (1998). Gibson proposed that two types of costs could contribute to structural complexity in real-time parsing: the storage cost and the integration cost, which draw on the same pool of working memory resources. Storage costs refers to the cost of keeping an element actively stored in memory while it cannot be interpreted and while other information in the sentence is being processed. The integration cost, on the other hand, refers to the cost of integrating a syntactic prediction at the time it can be satisfied. Further, these costs are both affected by locality, which is measured in relation to the number of new discourse referents being processed ${ }^{6}$. With respect to the processing cost that we refer to when the licensor in (10) is finally parsed, we specifically refer to the integration cost, which in this sentence is connected to the integration of the NPI with the licensor at the time the prediction for the appearance of the licensor is finally met. In previous ERP studies (e.g., Fiebach et al., 2002; Phillips et al., 2005), this integration cost has been shown to elicit a P600 at the position where the syntactic prediction is met. Further, as noted in footnote 4, its amplitude has been shown to reflect the degree of difficulty of the syntactic integration at hand; therefore, one would expect that a higher integration cost will be shown in terms of differences in the amplitude of the elicited ERP component.

\section{Paradigm Selection and Materials' Design}

In order to test the described contrast and implement the effects of increasing the linear distance between the NPI and negation (i.e., the licensor), Pablos et al. (submitted) introduced conditions that added one to two modifiers at either $\mathrm{A}$ or $\mathrm{B}$ positions in (10). These conditions were compared at the licensor position (i.e., negation) with a control such as (9b), where no additional material was introduced. As mentioned in the section that discusses the challenges for theoretically informed experimental research, the experimental paradigm must be carefully controlled to avoid introducing differences that can affect the results: the modifiers that were included always consisted of three words each and had no possible interference in the interpretation of the NPI besides delaying the appearance of negation ${ }^{7}$. In (11a) and (11b), we reproduce examples of the experimental materials with the modifiers that were included at the A position. Again, it was expected that this contrast would not result in a high integration processing cost (in the terms we defined above) at the licensor position (i.e., negation), as the modifiers 1 and 2 occur at a structural position where negation cannot appear.

\footnotetext{
${ }^{6}$ As we discuss in section Test Case 2, Warren and Gibson (2002) showed that the nature of the referring expression that has to be intergrated while a syntactic dependency or prediction is maintained can increase the syntactic complexity of the sentence. For example, indexical first and second person pronouns generate less syntactic complexity than indefinite or definite noun phrases, since the latter refer to less accessible discourse entities.

${ }^{7} \mathrm{We}$ consider that the content of these modifiers will not disrupt the on-line interpretation of the sentence, in particular in the search for a licensor once the NPI is parsed. In this sense, even if the modifiers are different in nature from parentheticals, we follow the assumptions made by work that used parentheticals to extend the linear distance of the elements within a long-distance dependency (see Dillon et al., 2014; Parker and Phillips, 2016, for examples).
} 
(11)

a. Dat het meisje ook maar iets [over dit vak $]_{\bmod 1}$ that the girl anything about this subject geleerd heeft is niet waarschijnlijk. learned has is not probable

'It is not probable that the girl has learned anything about this subject.'

b. Dat het meisje ook maar iets [over dit vak $]_{\bmod 1}[o p$ that the girl anything about this subject at de universiteit $]_{\bmod 2}$ geleerd heeft is niet the university learned has is not waarschijnlijk. probable

'It is not probable that the girl has learned anything about this subject in the university.'

On the other hand, in (12a) and (12b) modifiers were added to the main clause $B$ position, which occurs adjacent to the main verb "to be." It was expected that this contrast would result in a higher integration cost at negation due to the modifiers occurring at a structural position where negation can appear.

$$
\begin{aligned}
& \text { a. Dat het meisje ook maar iets geleerd heeft is } \\
& \text { that the girl anything learned has is } \\
& \text { [volgens haar docent }]_{\text {mod1 }} \\
& \text { according to her lecturer } \\
& \text { niet waarschijnlijk. } \\
& \text { not probable. }
\end{aligned}
$$

'According to her lecturer, it is not probable that the girl has learned anything.'

b. Dat het meisje ook maar iets geleerd heeft is

that the girl anything learned has is
[volgens haar docent $]_{\bmod 1}$
according to her lecturer
[vanwege haar afwezigheid $]_{\bmod 2}$ niet waarschijnlijk.
due to her absence not probable.

'According to her lecturer, it is not probable that the girl has learned anything due to her absence.'

Due to the fact that the NPI appears within a sentential subject clause, it is highly probable that the licensor is a negation (and not other NPI licensing environments such as conditionals, questions, etc.). Relevantly, in comparison with previous studies, the additional modifiers do not turn the test sentence into an ungrammatical continuation but rather add just extra information, avoiding effects due to grammaticality that can confound the interpretation of the results.

There are two types of potential effects that should be differentiated in the above manipulations. One is an integration cost effect from the fact that the dependency started at the NPI has decayed and retrieval of the NPI from memory when the licensor is found would be costly, and the other is a facilitation effect from the fact that negation is highly expected (and wanted) at the time the licensor is encountered. The third effect is an effect connected to the actual incremental integration of the added modifiers and the fact that their integration also delays the appearance of the licensor (negation). Again, if the predictions we set in the section Backward Negative Polarity Item (NPI) dependencies were met, we do not expect any effect with added modifiers in the A position [as in $(11 \mathrm{a}, \mathrm{b})]$, while effects are expected in the B position [as in $(12 \mathrm{a}, \mathrm{b})]$. Moreover, we expect to find an ERP component that is associated with syntactic integration costs and a difference in the amplitude of the ERP component to occur relative to the difficulty of integrating the syntactic prediction.

\section{Results and Discussion}

Results confirm the expected contrast between the conditions in (11a) and (11b), and those in (12a) and (12b) at the negation position, when compared with their baseline condition in (9b).

The statistical analysis of the data confirmed the presence of a significant central anterior negativity in the $200-600 \mathrm{~ms}$ time window at the position of negation when the control sentence in (9b) was compared to conditions (12a) and (12b) at negation. When (9b) was compared to (11a) and (11b) conditions, only a lower, non-significant difference emerged. As expected, the amplitude of the negativity showed a correlation with the position and number of modifiers in the sentence with respect to the position of negation. When modifiers are introduced at the main clause following the verb is (i.e., position $\mathrm{B}$ ), the amplitude of the central anterior negativity was bigger than when modifiers are introduced within the embedded clause after the NPI (i.e., position A). This shows that the parser is sensitive to structural positions in the sentence and that it considers the grammatical constraints for encoding the search for a location where a potential licensor for the NPI can occur. Furthermore, the results show that there is a different integration cost depending on the number of modifiers that are introduced at the potential licensor position.

While observable differences support the interpretation of the research question, the exact nature of the underlying process causing the ERP difference is questionable. Within the ERP literature in sentence comprehension, sustained negativities have been found for conditions that demanded a high memory load (e.g., Kluender and Kutas, 1993; King and Kutas, 1995; Friederici et al., 1996; Müller et al., 1997; Münte et al., 1998; Fiebach et al., 2002). In particular, they were found in studies that examined processing of dependencies of different lengths, where they manipulated linear distance from the start of the dependency to the closure point. These studies compared contexts of short vs. long-distance wh-questions (see Fiebach et al., 2002; Phillips et al., 2005) and object vs. subject relative clause contexts (King and Kutas, 1995). Furthermore, these studies carried out two types of analysis of the data. In the classic single-word ERP analysis they examined the ERPs at the beginning (i.e., wh-word or relativizer) and at the end of the dependencies (verb), whereas in the multiword ERP analysis of the data, they examined the ERPs elicited at each of the words of the dependency, from the beginning 
(e.g., wh-word) to the closure of the dependency (e.g. the verb $)^{8}$.

In the data from Pablos et al. (submitted), we take the beginning of the dependency to be marked by the NPI (i.e., the licensee) and the end marked by negation (i.e., the licensor). The position of negation is therefore the position where the dependency can be completed or finally integrated. It might be reasonable to think that the observed central anterior negativity marks the overall integration of the licensor for the NPI in sentences when the licensor-licensee distance is longer relative to the control. The size of the ERP amplitude is taken to reflect the level of disruption that additional material can cause in the search for a licensor. The fact that the effect correlates with the position of the intervening material (i.e., its size is relative to the position where the licensor is most likely to occur) suggests that structural conditions play a role in this process. As discussed in the section on NPI dependencies, previous studies that examined short vs. long-distance whquestions (see Fiebach et al., 2002; Phillips et al., 2005) have shown the elicitation of a P600 at the verb where the dependency is completed and have interpreted it as an integration cost related to the integration of the syntactic prediction. The fact that the type of dependency we examined is of a slight different nature (i.e., on the syntax-semantics interface) might have contributed to having a different type of ERP component elicited. Again, it should be emphasized that the study by Pablos et al. (submitted) does not examine cases of licensing failure as previous researchers have done in the experimental NPI literature. Instead, it looks at grammatical instances of NPI licensing where (a) the NPI occurs linearly preceding its licensor; and (b) what is manipulated is the delay of the occurrence of the licensor at different grammatical positions. This reasoning is a bit different in spirit from previous NPI research, but it allows us to draw a parallel between the two different kinds of backward dependencies presented in the section Test Case 1 in order to answer the question of whether the parser proceeds similarly in the strategies that it adopts when proceeding in the incremental interpretation of phenomena that occur long-distance.

\section{General Discussion of Experiments on Test Case 1}

Summarizing the main results of the ERP experiments discussed within our first test case, we first showed that gender mismatch effects in sentences containing cataphora result in anterior negativities in the $300-420 \mathrm{~ms}$ time-window when the gender of the antecedent mismatches that of the pronoun in no-constraint conditions. We then observed that (a) the delay in the appearance of the licensor in a structure with fronted NPIs results in a central anterior negativity in the 200-600 ms time-window at the position of negation and

\footnotetext{
${ }^{8}$ Notice that there is a problem inherent to the design and to the central question of our experiment and that is that we will never be able to match all the conditions closely, since they all differ in the number of words and modifiers. One potential solution would be to look at the ERP modulation of the whole sentence in a similar manner to Phillips et al. (2005), Fiebach et al. (2002), or King and Kutas (1995).
}

(b) the difference in ERP amplitude size for the anterior negativity reflects an increased integration cost correlated with the structural position where a licensor is allowed to appear.

The common finding of these ERP experiments is that the parser respects the grammatical restrictions posited in the two configurations. In the case of coreference, the parser did not try to link the pronoun with potential antecedents in positions where the grammar (i.e., Binding Principle C) prohibits coreference, due to c-command, a hierarchical relation. In the case of NPI backward licensing, only modifiers added immediately before the grammatically licit licensor affect the processing of this licensor, again because the licensor position that matters is the one in which a potential licensor can have scope over the NPI, which is a necessary condition for licensing it. Even though we are not able to directly compare the elicited ERP components (since they are generated for different stimuli and their latencies and topographies do not overlap completely), these results point to the application of grammatical constraints in the on-line interpretation of the stimuli. This idea is on a par with Parker and Phillips (2016), where dependencies that consist of subject-verb agreement or reflexive-antecedents are said to deploy the same memory access mechanisms despite differing in cue weightings.

Furthermore, if we abstract away from the elicited specific ERP components, we can claim that these results yield evidence for the existence of basic hierarchical relations in parsing. These hierarchical relations are an intrinsic property of our language capacity, therefore, the results support a one-system architecture (Lewis and Phillips, 2015), where the grammar and the parser are part of the same cognitive system (as discussed in the section that has examined the neural architecture of language). Being part of the same cognitive system does not necessarily entail that the heuristics need to come in the same form in both grammar and parser, but it seems logical to assume that some of the basic properties, such as hierarchical relations, are indeed universal and shared by both. As discussed by Phillips et al. (2011) and Kush et al. (2017), one relevant property present in both the cataphora and the backward NPI licensing cases discussed within our first test case is the directionality of the dependency, where the left-hand element provides reliable information in the prospective search for an antecedent in cataphoric dependencies and for a licensor in NPI licensing dependencies.

\section{TEST CASE 2: EXPERIMENTS ON WH-IN-SITU QUESTIONS IN MANDARIN CHINESE AND FRENCH}

As a second illustration of the points raised in the Introduction, in this section, we review a set of experiments where the same linguistic phenomenon is examined cross-linguistically to investigate the generalizability of parsing processes. The difference lays in the wh-question formation strategies available in the two tested languages. 
French is a language that employs two different strategies for question formation. Even though wh-in-situ is an option (13b), it also allows various types of structures which involve $w h$-fronting as in $(13 a)^{9}$ :
a. Qui tu as vu? who you have seen
'Who have you seen?'
b. $\mathrm{Tu}$ as vu qui ? you have seen who
'Who have you seen?'
c. Marie a vu Jean. Marie has seen Jean
'Marie has seen Jean.'

Whereas French has two different question formation strategies, Mandarin Chinese only has one, which we call the in-situ whquestion formation strategy. As shown in (14a), in this strategy the question word shéi "who" remains in its canonical position.

$$
\begin{aligned}
& \text { a. Ni zuótiān yùjiàn le shéi? } \\
& \text { you yesterday meet PERF who } \\
& \text { 'Who did you meet yesterday?' } \\
& \text { b. Lǐsì zuótiān yùjiàn le Zhāngsān. } \\
& \text { Lisi yesterday meet PERF Zhangsan } \\
& \text { 'Lisi met Zhangsan yesterday.' }
\end{aligned}
$$

As we can see in (13) and (14), in the case of wh-in-situ questions, the clause type of the sentence (question or declarative) is only apparent at the point the $w h$-word is encountered [as evidenced by the comparison between (13b) and (13c) and between (14a) and (14b)]. Crucially, no distinction can be made on the surface between these two sentences by readers as they process the sentence, unless there is prosodic or contextual information available. Therefore, sentences like those in (13b) and (14a) posit an interesting question with regard to parsing covert dependencies in that, if the sentence is read and it lacks any other kind of overt cue aiding its interpretation, there are different parsing heuristics that the parser might adopt.

The syntactic literature has claimed that although in-situ whquestions have no overt movement, they are formed via a covert dependency, where the wh-word can either relate to the left periphery (where the clause type of the sentence is flagged) via operator-variable binding, or via covert movement at Logical Form (LF; for further discussion see Huang, 1982; Cheng, 1991, 2009; Aoun and Li, 1993; Tsai, 1994; Bayer and Cheng, 2017). The

\footnotetext{
${ }^{9}$ Both $(13 a, b)$ are used in informal French only. In more formal registers, fronting is combined with subject-verb inversion or insertion of the question particle estce que. There are various pragmatic and grammatical differences between the fronting structure in (13a) and the in-situ one in (13b) as well as between the different possible fronting structures. For instance, the question word pourquoi is claimed to be bad in in-situ questions, while it is perfectly grammatical in most fronting questions, including the type illustrated in (13a) (Behnstedt, 1973). A full comparison between the different factors that may play a role in the choice between question strategies in French is beyond the scope of this article (but see, for instance, Boucher, 2010 for an overview).
}

theoretical proposals differ in the means by which the covertdependency is formed, but they share the core assumption that there is a higher position in the structure (i.e., SpecCP) where the clause type is marked. This in turn raises an interesting question with regard to their representation in the language processing system. Overt dependencies have been shown to trigger active search mechanisms as soon as a fronted $w h$-word is encountered (e.g., Crain and Fodor, 1985; Stowe, 1986), but the mechanism that the parser follows in interpreting in-situ wh-questions is not clear since there is no trigger (or cue) for a search for a whword/phrase. Therefore, the research questions that the current test case addresses are: (a) which are the processes involved in reading in-situ wh-questions where no overt trigger is present for the incremental buildup of the relevant dependency? and (b) which are the observable effects of establishing the dependency in the left periphery for the wh-phrase?

As a first attempt we can entertain two possible approaches for the processing of in-situ wh-phrases: (i) the parser always posits a covert dependency from the beginning of the sentence, and therefore postulates a silent structural position at the start of the parse, or (ii) the parser only realizes it needs to establish a covert dependency when it encounters the in-situ wh-word/phrase. If the parser adopts the first approach, there should not be any processing cost effect observable when comparing declarative and $w h$-in-situ questions, since both are equally considered from the beginning of the parse. With the latter strategy, at the insitu wh-word position, the parser will realize that a covert whdependency needs to be established, whereas this would not be necessary in declarative constructions. This effect should be similar in both Mandarin and French.

Moving one step further, it might also be possible that the integration and processing cost (see Gibson, 1998) for the covert operator position in the left periphery of a sentence differs depending on whether the language only has an in-situ question formation strategy (like Mandarin), or whether it is optionally in-situ (like French). In a language like French, once the fronted wh-question possibility has been discarded, the in-situ question continuation possibility may be less entertained. In Mandarin, where the in-situ strategy is the only one, the parser may anticipate the possibility of having a covert question operator, and thus encounter fewer difficulties in integrating the in-situ whexpression. Thus, a further research question is: to what extent is the parser able to anticipate the upcoming structure when there is no information available to determine the likelihood of encountering an in-situ question?

The study of the processing of covert dependencies in in-situ wh-questions in Mandarin Chinese has already been approached in the work of Xiang et al. (2013, 2015). Xiang et al. (2013, 2015) have examined the processing of insitu questions with complex wh-phrases with two different dependency lengths (with one embedding vs. mono clausal) and declaratives that contained definite noun phrases using different methodologies (i.e., Speed Accuracy Trade-Off (SAT), self-paced reading and eye-tracking). Xiang et al. (2013, 2015) found that in-situ wh-questions were processed slower, especially when in-situ wh-questions with one embedding were compared with mono-clausal questions. Nevertheless, there are still some 
questions that remain concerning the generalizations that we can make regarding the processing of in-situ wh-questions. This is so because in the psycholinguistics literature both complex wh-phrases and definite noun phrases have been claimed to involve higher processing cost, that is, connected to the increase of the complexity of the parse, as we have discussed in the section on NPI dependencies (see also footnote 6). In complex wh-phrases, for example, the processing cost is said to be attributed to the discourse-linking nature of these wh-phrases (see De Vincenzi, 1996; Kaan et al., 2000; Donkers et al., 2013), whereas in the case of definite noun phrases, the processing cost is due to the fact that they refer to discourse entities that are less accessible and to their position in the Accessibility Hierarchy (see Ariel, 1990; Gundel et al., 1993; Warren and Gibson, 2002). Furthermore, since there is theoretical research showing that $w h$-words are closer to indefinites (see Huang, 1982; Cheng, 1991, among others), the self-paced reading experiments we report here addressed these issues connected to syntactic complexity by including an additional comparison between declarative sentences with definite and indefinite noun phrases with questions, in contexts where the wh-phrase was simplex (qui "who" and shéi "who") or contexts where the wh-phrase was complex (such as quel ami "which friend" in French and năgè péngyǒu "which friend" in Mandarin Chinese).

In testing the phenomenon of in-situ wh-questions, Pablos et al. (submitted) wanted to compare how the incremental reading of $i n$-situ $w h$-questions proceeds in comparison to the reading of their declarative counterparts that contain the exact same content up to the wh-word/noun phrase position. Their aim was two-fold: first, they wanted to investigate if the whword/phrase is expected, and if its integration is expected to be without any additional cost in comparison to its declarative counterpart; and second, they wanted to investigate whether the available $w h$-question formation strategies in each language have an impact on the initial hypotheses that are being considered by the parser before the wh-word/phrase position is encountered. The next section discusses the results of the four reading time experiments in Pablos et al. (submitted) on the processing of wh-in-situ questions in French and Mandarin Chinese.

\section{Processing Simplex wh-in-Situ Questions in French}

The first of the four self-paced reading experiments in Pablos et al. (submitted) examined the contrast shown in (15) in order to test whether reading time differences can be found between questions and declaratives. To limit spurious effects, care was taken in the design of the materials: (i) the wh-word qui "who" in (15a) and the indefinite noun phrase quelqu'un "someone" in (15b) remain constant throughout the whole experiment; (ii) in the definite noun phrase condition, mono- and disyllabic proper names were used ${ }^{10}$ to provide a match both with the length of the wh-word qui and the indefinite noun phrase quelqu'un, as

\footnotetext{
${ }^{10}$ Proper Names are known to result in higher processing cost than other referential noun phrases (see Warren and Gibson, 2002 for further discussion). We chose Proper Names for our design because they were the definites that consisted of single words.
}

illustrated in (15c); (iii) all other elements among conditions were kept minimally different.
a. In-situ question with a simplex wh-phrase Le braqueur de banque a blessé qui dans sa the robber of bank hashurt whom on his fuite? escape
'Who has the bank robber hurt on his escape?'
b. Declarative with indefinite object noun phrase Le braqueur de banque a blessé quelqu'un dans sa the robber of bank hashurt someone on his fuite. escape

'The robber of the bank has hurt someone on his escape.'

c. Declarative with Proper Name object Le braqueur de banque a blessé Marie/Jean dans sa the robber of bank hashurt Marie/Jean on his fuite. escape

'The robber of the bank has hurt Marie/Jean on his escape.'

Considering the predictions of the two possible parsing approaches described above, if only a declarative interpretation was assumed from the beginning of the sentence, the parser would need to reanalyze its initial assumption, which in turn will result in reading time differences between the declarative sentences in (15b) and (15c) and the question in (15a) at the whword/noun phrase position. Conversely, if the parser considers in parallel both possible interpretations, no reading time differences are expected between the question and the declarative conditions.

Comparison of the residual reading times of the sentences in (15) shows that there is a difference in processing times between declaratives and in-situ questions with a simple whphrase starting from the $w h$-word/noun phrase position. The timing of this difference depends on the type of declarative. When it contains an indefinite such as quelqu'un "someone" in (15b), the difference between questions and declaratives occurs as soon as the $w h$-word is encountered, whereas when it contains a proper name such as Marie in (18c), this difference only occurs once the proper name has been interpreted at the immediately following region [i.e., the preposition dans "in" within the examples in (15)].

\section{Processing Complex wh-in-Situ Questions in French}

The second experiment examined the processing of questions and declaratives containing complex $w h$-phrases/noun phrases. The stimuli followed the form of the simplex wh-question experiment, where changes between the two experiments were only implemented at the $w h$-phrase/noun phrase position. An example of a set of materials is given in (16), with a complex wh-phrase quelle caissière "which cashier" in the wh condition in (16a), declaratives with an indefinite noun phrase une caissière "a cashier" in (16b) and declaratives with a definite noun phrase la caissière "the cashier" in (16c). 
(16) a. In-situ question with a complex wh-phrase

Le braqueur de banque a blessé quelle caissière the robber of bank hashurt which cashier dans sa fuite? in his escape?

'Which cashier has the bank robber hurt on his escape?'

b. Declarative with indefinite object noun phrase Le braqueur de banque a blessé une caissière dans the robber of bank hashurt a cashier in sa fuite. his escape.

'The bank robber hurt a cashier on his escape.'

c. Declarative with definite object noun phrase

Le braqueur de banque a blessé la caissière dans the robber of bank hashurt the cashier in sa fuite. his escape.

'The bank robber has hurt the cashier on his escape.'

The same predictions about the two possible parsing approaches described in the case of simplex $w h$-phrases are applicable to the comparison between complex wh-phrases and declaratives. Our results show that in-situ questions with a complex whphrase such as quelle caissière "which cashier" in (16a) are again significantly slower to read than declaratives that contain an indefinite noun phrase such as une caissière "a cashier" in (16b). Interestingly, this effect is not apparent until the whole whphrase has been processed, since the effect appears at the word immediately after the wh-phrase (i.e., the preposition dans "in"). Note that quel(le) is the determiner of the interrogative whphrase, and the participants clearly waited until the end of the wh-phrase. Furthermore, given that noun phrases in French can have post-nominal modification (quelle caissière débordée "which overworked cashier" or quelle caissière de supermarché "which grocery store cashier"), the effect might be due to readers not considering the wh-phrases to be completed until they reached the region immediately following the noun.

\section{General Discussion of Experiments on Processing French in-Situ wh-Questions}

Results from both the simplex and complex in-situ wh-questions in French showed that questions containing both type of whphrases are generally processed slower than their declarative counterparts, in particular those declaratives that contain indefinite noun phrases such as quelqu'un "someone" in (15b) and une caissière "a cashier" in (16b). We discuss the implications of these findings in connection to those of the self-paced readings on Mandarin Chinese in the general discussion of experiments on test case 2 .

\section{Processing Simplex wh-in-Situ Questions in Mandarin Chinese}

The same paradigm as in the French experiment described in the section Processing Simplex wh-in-situ Questions in French was used in Mandarin Chinese by Pablos et al. (submitted), contrasting wh-in-situ questions with declarative sentences. In the object position, the wh-word shéi "who" was used in the wh-questions and rén "someone" (indefinite) or a proper name (definite) in declaratives.

Again, three conditions were designed to test whether reading time differences can be found between questions and declaratives in Mandarin Chinese. As in French, care was taken to minimize the differences between conditions to avoid unintentional bias of the results due to uncontrolled effects: (i) The wh-word shé "who" in (17a) and the indefinite noun phrase rén "someone" in (17b) are monosyllabic and they were not changed throughout the whole experiment, whereas the proper names in $(17 \mathrm{c})$ were varied in having different bisyllabic proper names all throughout $^{11}$; (ii) in order to make sure that the indefinite rén "someone" had only the indefinite interpretation available, intensional verbs were used and the perfective marker -le was omitted (see Cheng and Sybesma, 1999 for further discussion); (iii) the use of intensional predicates allowed for two extra regions after the $w h$-word/phrase position, which occurs usually sentence finally in Mandarin Chinese, to avoid confounds of sentence wrap-up effects at the wh-word position.

(17) a. In-situ question with a simplex phrase 那个男生 想要 求 谁 解决问题?

Nàgè nánshēng xiǎngyào qiú shéi jiějué wèntí? the $e^{12}$ boy want beg who solve problem

'Who did the boy want to beg to solve the problem?'

b. Declarative with indefinite object noun phrase

那个 男生 想要 求人

Nàgè nánshēng xiăngyào qiú rén

the boy want beg person

解决 问题.

jiějué wèntí.

solve problem

'The boy wants to beg someone to solve the problem.'

c. Declarative with Proper Name object

那个 男生 想要 求 小张

Nàgè nánshēng xiăngyào qiú Xiǎozhāng

the boy want beg Xiaozhang

解决 问题.

jiějué wèntí.

solve problem

'The boy wants to beg Xiaozhang to solve the problem.'

The results of in-situ questions with a simplex wh-phrase in Mandarin Chinese show that in-situ questions with a simplex whphrase [shéi "who" in (17a)], were read significantly slower than their indefinite declarative counterparts [rén "person/someone" in (17b)] immediately after the wh-word, at the verb jiejué "to solve." However, at the wh-word position shéi "who" in (17a), in-situ questions are significantly faster than their Proper Name counterparts in (17c). This slowdown effect at the proper name is attributed to two possible reasons:

\footnotetext{
${ }^{11}$ In Mandarin Chinese proper names are at least bisyllabic. This is the reason why, bisyllablic proper names are used in the study even though their corresponding interrogative and indefinite counterparts are monosyllabic.

${ }^{12} \mathrm{Nà} \mathrm{"that"} \mathrm{in} \mathrm{Chinese} \mathrm{is} \mathrm{a} \mathrm{demonstrative} \mathrm{which} \mathrm{is} \mathrm{often} \mathrm{used} \mathrm{without} \mathrm{a} \mathrm{distal}$ demonstrative reading. In such cases, its reading is more like a definite article (see Huang, 1999).
} 
(1) proper names in the experiment materials having two morphemes/syllables while the question word shéi "who" only has one ${ }^{13}$ and (2) the processing of proper names in Mandarin Chinese has been shown to be more costly than the processing of common nouns (see Yen, 2007).

\section{Processing Complex wh-in-Situ Questions in Mandarin Chinese}

The fourth and final experiment in Mandarin Chinese from Pablos et al. (submitted) used the same paradigm as the French experiment that tested the processing of complex whin-situ questions in French, by contrasting wh-in-situ questions with declarative sentences. The stimuli followed the form as the simplex wh-question experiment described in the previous section. It only differed in content at the position of the whphrase/noun phrase: a complex wh-in-situ constituent [e.g., năgè tóngxué "which classmate" in (18a)] was contrasted with complex noun phrases of two types [e.g., the indefinite yígè tóngxué "a classmate" in (18b) and the definite nàgè tóngxué "the classmate" in $(18 \mathrm{c})]$.

(18) a. In-situ question with a complex phrase 那个男生 想要 求那个同学 Nàgè nánshēng xiăngyào qiú năgè tóngxué the boy want beg which classmate 解决 问题?

jiějué wèntí? solve problem

'Which classmate does the boy want to beg to solve the problem?'

b. Declarative with indefinite object noun phrase $\begin{array}{lllll}\text { 那个 男生 } & \text { 想要 } & \text { 求 一个 } & \text { 同学 } \\ \text { Nàgè nánshēng } & \text { xiăngyào qiú yígè tóngxué } \\ \text { the boy } & \text { want } & \text { beg a } & \text { classmate }\end{array}$ 解决 问题.

jiějué wèntí.

solve problem

'The boy wants to beg a classmate to solve the problem.'

c. Declarative with definite object noun phrase

那个男生 想要 求 那个同学

Nàgè nánshēng xiăngyào qiú nàgè tóngxué

the boy want beg the classmate

解决 问题.

jiějué wèntí.

solve problem

'The boy wants to beg the classmate to solve the problem.'

The results show that, when the wh-phrase is encountered, insitu questions with a complex wh-phrase in Mandarin are slower at the wh-determiner position of the wh-phrase năgè "which" than their declarative counterparts containing an indefinite (i.e., yígè " $a$ "). Furthermore, the slowdown carries on to the following noun region [i.e., tóngxué "classmate" in (18)]. At this noun, the definite declarative is still slower than the indefinite declarative.

\footnotetext{
${ }^{13}$ As discussed in footnote 11 , in order to use completely natural stimuli for Mandarin, we could only use bisyllabic proper names.
}

Based on these results, Pablos et al. (submitted) concluded that in-situ questions with a complex wh-phrase are processed significantly slower than declaratives with an indefinite noun phrase at the whole phrase; while they are only processed significantly slower than declaratives with a definite noun phrase at the noun position. These researchers connect processing differences at the wh-word năgè "which," to the discourse-link (Pesetsky, 1987; Avrutin, 2000) related cost, a well-known fact in the processing literature (see De Vincenzi, 1996; Kaan et al., 2000; Donkers et al., 2013; and for opposite claims see Frazier and Clifton, 2002; Hofmeister and Sag, 2010, among others). This means that when no prior context is given, the discourse-link feature in năgè "which" leads to similar additional processing cost as that in the definite determiner nàge "the" (assuming that definites are costlier than indefinites as discussed by Warren and Gibson, 2002). In contrast, no additional processing cost is found when processing indefinite yígè "a" because the indefinite does not require prior discourse information.

\section{General Discussion of Experiments on Mandarin Chinese in-Situ wh-questions}

The results from the processing of in-situ questions with a simplex and a complex wh-phrase in Mandarin Chinese show that, overall, both wh-phrase types (i.e., simplex and complex) are processed slower than the indefinite noun phrases within declaratives (i.e., rén "someone/person" and yígè tóngxué "a classmate"), but these effects show different timing properties depending on whether the $w h$-phrase is complex or simplex.

Based on the hypotheses put forth in the section Test Case 2 for wh-question formation strategies across languages, the results obtained by Pablos et al. (submitted) for the processing of in-situ questions containing complex and simplex wh-phrases in Mandarin support the approach in which the question interpretation is only considered when the wh-phrase is encountered, and not before. Nevertheless, this prediction seems to only be met when differences between in-situ whquestions and declaratives containing indefinite noun phrases are taken into consideration. Declaratives that contain definite noun phrases do not seem to pattern accordingly. Researchers have previously identified the reading time cost of proper names and definite noun phrases over indefinite noun phrases in the processing literature (see Warren and Gibson, 2002; Yen, 2007). Thus, this result is consistent with previous findings.

\section{General Discussion of Experiments on Test Case 2}

In the four self-paced reading experiments on the processing of in-situ simplex and complex wh-questions in French and Mandarin Chinese, results show that both simplex and complex wh-questions are generally processed slower than declaratives with indefinite noun phrases. Overall, the results suggest that, as hypothesized by one of the processing strategies discussed in Test Case 2, speakers of French and Mandarin do not seem to consider the in-situ wh-question interpretation of the sentences until they encounter the $w h$-word/phrase. This seems to occur regardless of whether the language has different wh-question 
formation strategies or whether the only available strategy is the in-situ wh-question formation.

This suggests that the same processing mechanism is used in these two languages when no prosodic or contextual information is being considered. Furthermore, the results are compatible with the theoretical analyses of in-situ wh-questions involving covert dependencies between the in-situ item and the left-periphery.

As seen in the previous sections on the Mandarin and French experiments, we matched the experimental paradigms that we used for French and Mandarin as closely as possible bearing in mind the differences between the two languages. This strong parallelism provided us with the opportunity to see which effects were maintained across languages despite their differences and which effects could connect to the restrictions imposed by the research question that we pursued and the experimental technique we used. For example, the timing and length of the observed effects did not always coincide for both languages. This is very likely to be dependent on specific characteristics of the language and the data used, which point to several processes occurring at same time (e.g., dependency completion, referential assignment, etc.). The measurement of the effects by means of reading time differences can therefore not be conclusively associated to a single processing task, but might be connected to several other processes involved in the on-line comprehension of these constructions. Nevertheless, if we consider the overall result, the observable differences confirm the presence of online incremental interpretational processes in both languages. The results suggest that in both languages, the parser does not postulate the possibility of a question operator in CP before encountering the in-situ wh expression. Furthermore, the evidence coming from a close comparison of the two languages points to the existence of a common processing strategy adopted by their speakers.

\section{GENERAL DISCUSSION}

In the previous sections, we have discussed two ways to conduct strongly theoretically informed experimental studies. In the first test case, we examined the processing of backward dependencies using two different linguistic phenomena (the referential interpretation of cataphoric pronouns and NPI licensing), with one method and one language. In the second test case, we examined the processing of one linguistic phenomenon (in-situ wh-questions) in different languages using a uniform method of testing and as closely as possible matched linguistic paradigms. The objective of these two tests cases was twofold: (1) to assess whether we can find common strategies in the processing of different backward dependencies and (2) to investigate whether there is a common strategy in how wh-in-situ questions are processed across languages.

Considering the evidence provided by the test cases discussed within this article, we can draw two major conclusions: (1) that the parser respects grammatical constraints, which means it is sensitive to differences in (hierarchical) structure, and (2) that there is a common parsing procedure for in-situ whquestion parsing phenomena in languages with different question formation strategies, where the analysis of the sentence as a wh-question does not seem to be assumed until overt evidence such as the $w h$-word/phrase is found in the input.

Based on what we have discussed so far, the question that remains is how our experimental results can feed theoretical linguistics or what insight can we gain from these results. In other words, how can our results contribute to the linking hypothesis discussed by Embick and Poeppel (2015). There are two possible reasons why this research can be relevant for theoretical linguistics. The first is more straitghforward, as it is connected to testing the same phenomenon in different languages with different question formation options. If the existing question formation strategies in these languages do not seem to make any difference for their parsing, then it means that at some level they share some basic properties. The main syntactic analyses of insitu wh-questions assume a covert dependency (either through covert movement or a question operator binding with the in-situ element). The reported results are consistent with the establishing of a covert dependency (without choosing the particular type of ways to establish the covert dependency). The second is a more challenging one, since it comes from phenomena that are conceptually the same but different in their realization. The argument here would be that, if we find that the parser responds similarly to hierarchical relations, despite differences in the configuration of each tested structure, then it has to be the case that the parser can extract general grammatical properties out of specific input and that it can deduce the structural hierarchy behind the linearly presented input.

As discussed in the discussion of the challenges for theoretically informed experimental research in linguistics, there is usually some simplification of the theoretical question when searching for a suitable experimental paradigm. In our test cases, the starting theoretical question is much more complex than the evidence that we obtain, which supports there being hierarchical relations, for example. This means that, as researchers, we have to be aware of there being some theoretical questions that we are not going to be able to address yet. In particular, when we consider the relative maturity of the field of experimental linguistics, our current insight on experimental methods and procedure, there still exists a margin between the pursued theoretical question and the obtained results, i.e., the so-called Granularity Mismatch Problem in Poeppel and Embick's (2005) terms.

Finally, on the empirical side, our results are in line with current research that is connected to strongly theoretically based questions, such as the processing of Strong and Weak Crossover dependencies. For example, the research by Kush et al. (2017) also tries to examine how an incremental parser might interpret dependencies that can only be made licit once the right-hand of the sentence is known, which is comparable to the experiments on the processing of $w h$-in-situ questions. This is crucial when we compare this type of dependencies with the backward dependency cases, where the expectation for a licensor is turned into a forward search. This implies that backward and forward processes engage different parsing processes: in the case of backward dependencies there is a search for the licensor started at the licensee (the pronoun or NPI in our test case 1), whereas in the in-situ questions there is a retrieval or backward search for a 
licensor started at the licensee (the $w h$-word/phrase). There is an overall tendency in the field of psycholinguistics to compare the processing of dependencies with similar characteristics in terms of retrieval and attraction processes in order to shed further light into how closely the parser follows the constraints of grammar. Work from Parker and Phillips (2016, 2017), for example, has compared licensor-NPI, reflexive-antecedent and subject-verb agreement dependencies in an attempt to investigate how much these dependencies look alike in their parsing routines. Our first test case on the processing of backward dependencies connects with this research in that dependencies that seem apparently quite different in their realization can show a similar processing behavior.

To conclude, it seems to us that the only way to reach some maturity in the field of experimental linguistics research is to generate a big pool of evidence that builds upon showing some of the basic properties of language in performance across different languages, so that, with time, it will be possible to find evidence for more complex relations, enabling us to bring theory and experimental evidence closer.

\section{AUTHOR CONTRIBUTIONS}

LP, JD, and LC conceived the project, were involved in all aspects of the design of the proposed methodology as well as on the interpretation of the results. LP was involved in the experiment creation and implementation, data analysis and contributed to drafting the manuscript. JD and LC critically revised the manuscript. All authors are responsible for final approval of the version to be published.

\section{ACKNOWLEDGEMENTS}

We would like to thank the following colleagues for their help in different stages of this work. Yang Yang for her help in the

\section{REFERENCES}

Aoun, J., and Li, A. Y.-H. (1993). Wh-elements in-situ: syntax or LF? Ling. Inquiry 24, 199-238.

Ariel, M. (1990). Accessing Noun-Phrase Antecedents. London: Routledge.

Arnal, L. H., Poeppel, D., and Giraud, A. L. (2015). Temporal coding in the auditory cortex. Handb. Clin. Neurol. 129, 85-98. doi: 10.1016/B978-0-444-62630-1.00005-6

Avrutin, S. (2000). Comprehension of discourse-linked and non-discourse-linked questions by children and Broca's aphasics. Lang. Brain Represent. Proces. 295-313. doi: 10.1016/B978-012304260-6/50017-7

Bayer, J., and Cheng, L. L. S. (2017). "Wh-in-situ," in The Blackwell Companion to Syntax, 2nd Edn., eds M. Everaert and H. van Riemsdijk (Hoboken, NJ: Wiley-Blackwell Publishing), 1-44. doi: 10.1002/9781118358733.wbsyncom106

Behnstedt, P. (1973). Viens-tu? Est-ce que tu viens? Tu viens? Formen und Strukturen des direkten Fragesatzes im Französischen (Tübinger Beiträge zur Linguistik 41). Tübingen: Gunter Narr.

Bemis, D. K., and Pylkkänen, L. (2011). Simple Composition: a magnetoencephalography investigation into the comprehension of minimal linguistic phrases. J. Neurosci. 31, 2801-2814. doi: 10.1523/ JNEUROSCI.5003-10.2011

Bever, T. G. (1970). “The cognitive basis for linguistic structures," in Cognition and the Development of Language, ed J. R. Hayes (New York, NY: Wiley), 279-362. generation, testing, analysis, and interpretation of the self-paced reading studies in Mandarin Chinese. Bobby Ruijgrok for his help in the generation of the Dutch GMM stimuli and in testing the ERP study at Leiden University. Erik Schoorlemmer for his help in the generation of the Dutch NPI stimuli. Sylvie Cuchet, Lucas Tual, Juliette Angot, and Hamida Demirdache for their help in the testing of the self-paced reading studies in French. Xiaolu Yang for her help in conducting the self-paced readings in Mandarin Chinese. Nina Kazanina for her willingness to share her English materials for the Dutch GMM ERP study and her valuable feedback regarding the interpretation of both ERP studies. Masaya Yoshida, Ming Xiang, and Nayoung Kwon for their feedback on the analysis and interpretation of the self-paced reading studies on Mandarin Chinese. Niels O. Schiller for his feedback on the generation and interpretation of the Dutch ERP studies and for providing insightful feedback for all the studies included within this article. And last but not least, Stella Gryllia and Aliza Glasbergen-Plas for helping out tremendously with their feedback at different stages of the generation, testing, analysis, and interpretation of the experiments on in-situ wh-questions in Mandarin Chinese and French. Earlier versions of this work were presented at the following conferences: Architectures and Mechanism of Language Processing (AMLaP) in 2011, 2015, and 2016, CUNY Human Sentence Processing Conference in 2012, GLOW35 in 2012, CNS in 2014, the 3rd East Asian Psycholinguistics Colloquium (EAPC3) in 2015, the XII International Symposium of Psycholinguistic in 2015, and at the Language and Cognition Group (LACG) at Leiden University Centre for Linguistics (LUCL). We thank the audiences of all these conferences and discussion group for their input. The research in this article was partly funded by The Netherlands Organisation for Scientific Research (NWO) 10.13039/501100003246 within the project Understanding Questions (Grant: 360-70-480).

Boucher, P. (2010). "Wh-questions in French and English," in Comparative and Contrastive Studies of Information Structure, eds C. Breul and E. Göbbel (Amsterdam: John Benjamins Publishing Company), 101-138.

Brennan, J., Nir, Y., Hasson, U., Malach, R., Heeger, D. J., and Pylkkänen, L. (2012). Syntactic complexity predicts anterior temporal activity during natural story listening. Brain Lang. 120, 163-173. doi: 10.1016/j.bandl.2010. 04.002

Cheng, L. L. S. (2009). Wh-in-situ from the 1980s to now. Lang. Linguist. Compass 3, 767-791. doi: 10.1111/j.1749-818X.2009.00133.x

Cheng, L. L.-S. (1991). On the Typology of Wh-questions. Ph.D. dissertation, MIT, Garland Publishers.

Cheng, L. L.-S., and Sybesma, R. P. E. (1999). Bare and not so bare nouns and the structure of NP. Ling. Inquiry 30, 509-542. doi: 10.1162/0024389995 54192

Chomsky, N. (1965). Aspects of the Theory of Syntax. Cambridge, MA: MIT Press. Chomsky, N. (1981). Lectures on Government and Binding. Dordrecht: Foris.

Crain, S., and Fodor, J. D. (1985). "How can grammars help parsers?" in Natural Language Parsing. Psychological, Computational, and Theoretical Perspectives, eds D. Dowty, L. Karttunen, and A. M. Zwicky (Cambridge: Cambridge University Press), 94-128.

De Vincenzi, M. (1996). Syntactic analysis in sentence comprehension: effects of dependency types and grammatical constraints. J. Psycholinguist. Res. 25, 117-133. doi: 10.1007/BF01708422 
Dillon, B., Clifton, C. Jr., and Frazier, L. (2014). Pushed aside: parentheticals, memory, and processing. Lang. Cogn. Neurosci. 29, 483-498. doi: $10.1080 / 01690965.2013 .866684$

Ding, N., Melloni, L., Zhang, H., Tian, X., and Poeppel, D. (2015). Cortical tracking of hierarchical linguistic structures in connected speech. Nat. Neurosci. 19, 158-164. doi: 10.1038/nn.4186

Donkers, J., Hoeks, J. C. J., and Stowe, L. A. (2013). D-linking or setrestriction? Processing Which-questions in Dutch. Lang. Cogn. Process. 28, 9-28. doi: 10.1080/01690965.2011.566343

Drenhaus, H., Blaszczak, J., and Schütte, J. (2007). "Some psycholinguistic comments on NPI licensing," in Proceedings of Sinn und Bedeutung, Vol. 11, ed E. Puig-Waldmüller (Barcelona: Universitat Pompeu Fabra), 180-193.

Drenhaus, H., Saddy, D., and Frisch, S. (2005). "Processing negative polarity items: when negation comes through the backdoor," in Linguistic Evidence-Empirical, Theoretical, and Computational Perspectives, eds S. Kepser and M. Reis (Berlin: Mouton de Gruyter), 145-165.

Embick, D., and Poeppel, D. (2015). Towards a computational(ist) neurobiology of language: correlational, integrated and explanatory neurolinguistics. Lang. Cogn. Neurosci. 30, 357-366. doi: 10.1080/23273798.2014.980750

Fiebach, C. J., Schlesewsky, M., and Friederici, A. (2002). Separating syntactic memory costs and syntactic integration costs during parsing: the processing of German WH-questions. J. Mem. Lang. 47, 250-272. doi: 10.1016/S0749-596X(02)00004-9

Fodor, J. A., Bever, T. G., and Garrett, M. (1974). The Psychology of Language. New York, NY: McGraw Hill.

Frazier, L., and Clifton, C. Jr. (2002). Processing "d-linked" phrases. J. Psycholinguist. Res. 31, 633-660. doi: 10.1023/A:1021269122049

Friederici, A. D., Mecklinger, A., Spencer, K. M., Steinhauer, K., and Donchin, E. (2001). Syntactic parsing preferences and their on-line revisions: a spatiotemporal analysis of event-related brain potentials. Cogn. Brain Res. 11, 305-323. doi: 10.1016/S0926-6410(00)00065-3

Friederici, A. D., Mecklinger, A., and Hahne, A. (1996). The temporal structure of syntactic parsing: early and late event-related brain potential effects elicited by syntactic anomalies. J. Exp. Psychol. Learn. Mem. Cogn. 22, $1219-1248$. doi: 10.1037/0278-7393.22.5.1219

Fruchter, J., and Marantz, A. (2015). Decomposition, Lookup, and Recombination: MEG evidence for the Full Decomposition model of complex visual word recognition. Brain Lang. 143, 81-96. doi: 10.1016/j.bandl.2015.03.001

Fruchter, J., Linzen, T., Westerlund, M., and Marantz, A. (2015). Lexical preactivation in basic linguistic phrases. J. Cogn. Neurosci., 27, 1912-1935. doi: 10.1162 /jocn_a_00822

Giannakidou, A. (2011). "Negative and positive polarity items," in Semantics: An International Handbook of Natural Language Meaning de Gruyter, eds H. von Klaus, C. Maienborn, and P. Portner (Berlin: Mouton de Gruyter), 1660-1712.

Gibson, E. (1998). Linguistic complexity: locality of syntactic dependencies. Cognition 68, 1-76. doi: 10.1016/S0010-0277(98)00034-1

Gundel, J., Hedberg, H., and Zacharski, R. (1993). Referring expressions in discourse. Language 69, 274-307. doi: 10.2307/416535

Hagoort, P., Brown, C., and Groothusen, J. (1993). The syntactic positive shift as an ERP-measure of syntactic processing. Lang. Cogn. Process. 8, 439-483. doi: $10.1080 / 01690969308407585$

Hoeksema, J. (2000). "Negative polarity Items: triggering, scope and c-command," in Negation and Polarity: Syntactic and Semantic Perspectives, eds L. R. Horn and Y. Kato (Oxford; New York, NY: Oxford University Press), 147-192.

Hoekstra, E. (1991). Licensing Conditions on Phrase Structure. Ph.D. dissertation. University of Groningen.

Hofmeister, P., and Sag, I. A. (2010). Cognitive constraints and island effects. Language (Baltim) 86, 366-415. doi: 10.1353/lan.0.0223

Huang, C. -T. J. (1982). Logical Relations in Chinese and the Theory of Grammar. Ph.D. Dissertation, MIT.

Huang, S. F. (1999). The emergence of a grammatical category definite article in spoken Mandarin. J. Pragmat. 31, 77-94. doi: 10.1016/S0378-2166(98)00052-6

Kaan, E., Harris, A., Gibson, E., and Holcomb, P. (2000). The P600 as an index of syntactic integration difficulty. Lang. Cogn. Process. 15, 159-201. doi: $10.1080 / 016909600386084$

Kazanina, N., Lau, E. F., Lieberman, M., Yoshida, M., and Phillips, C. (2007). The effect of syntactic contraints on the processing of backwards anaphora. J. Mem. Lang. 56, 384-409. doi: 10.1016/j.jml.2006.09.003
Kimball, J. (1973). Seven principles of surface structure parsing in natural language. Cognition 2, 15-47. doi: 10.1016/0010-0277(72)90028-5

King, J. W., and Kutas, M. (1995). Who did what and when? using word- and clause-level ERPs to monitor working memory usage in reading. J. Cogn. Neurosci. 7, 376-395. doi: 10.1162/jocn.1995. 7.3.376

Kluender, R., and Kutas, M. (1993). Bridging the gap: evidence from ERPs on the processing of unbounded dependencies. J. Cogn. Neurosci. 5, 196-214. doi: 10.1162/jocn.1993.5.2.196

Kush, D., Lidz, J., and Phillips, C. (2017). Looking forwards and backwards: the real-time processing of Strong and Weak Crossover. Glossa 2, 1-29. doi: $10.5334 /$ gjgl.280

Levelt, W. J. M. (1970). "A scaling approach to the study of syntactic relations," in Advances in Psycholinguistics, eds G. B. Flores d'Arcais and W. J. M. Levelt (New York, NY: American Elsevier), 109-121.

Lewis, S., and Phillips, C. (2015). Aligning grammatical theories and language processing models. J. Psycholinguist. Res. 44, 27-46. doi: 10.1007/s10936-014-9329-z

Luo, H., and Poeppel, D. (2007). Phase patterns of neuronal responses reliably discriminate speech in human auditory cortex. Neuron 54, 1001-1010. doi: 10.1016/j.neuron.2007.06.004

Marantz, A. (2005). Generative linguistics within the cognitive neuroscience of language. Ling. Rev. 22, 429-445. doi: 10.1515/tlir.2005.22.2-4.429

Marantz, A. (2013). No escape from morphemes in morphological processing. Lang. Cogn. Process. 28, 905-916. doi: 10.1080/01690965.2013.779385

Müller, H. M., King, J. W., and Kutas, M. (1997). Event-related potentials elicited by spoken relative clauses. Cogn. Brain Res. 5, 193-203. doi: 10.1016/S0926-6410(96)00070-5

Münte, F., Schiltz, K., and Kutas, M. (1998). When temporal terms belie conceptual order. Nature 395, 71-73. doi: 10.1038/25731

Nelson, M. J, El Karoui, I., Giber, K., Yang, X., Cohen, L., Koopman, H., et al. (2017). Neurophysiological dynamics of phrase-structure building during sentence processing. Proc. Natl. Acad. Sci. U.S.A. 114, E3669-E3678. doi: $10.1073 /$ pnas. 1701590114

Osterhout, L., and Holcomb, P. (1992). Event-related brain potentials elicited by syntactic anomaly. J. Mem. Lang. 31, 785-806. doi: 10.1016/0749-596X(92)90039-Z

Osterhout, L., and Mobley, L. A. (1995). Event-related brain potentials elicited by failure to agree. J. Mem. Lang. 34, 739-773. doi: 10.1006/jmla.1995.1033

Pablos, L. (2009). "Subjunctive mood and NPI licensing in Spanish," in Poster Presented at Architectures and Mechanisms for Language Processing AMLaP 2009 (Barcelona: University Pompeu Fabra).

Pablos, L., and Saddy, J. D. (2009). "NPIs and complementizer agreement in basque," in Papers from Brain Talk: Discourse with and in the Brain, eds $\mathrm{K}$. Alter, M. Horne, M. Lindgren, M. Roll, and J. von Koss Torkildsen (Lund: Lund University), 3-21.

Pablos, L., Doetjes, J., Ruijgrok, B., and Cheng, L. L.-S. (2015). Active search for antecedents in cataphoric pronoun resolution. Front. Psychol. 6:1638. doi: 10.3389/fpsyg.2015.01638

Pablos, L., Shirley, E., Erdocia, K., Laka, I., Williams, N., and Saddy, J. D. (2011). "Licensing of NPIs in Basque: an ERP Study," in Poster Presented at the 10th International Symposium of Psycholinguistics (Donostia).

Pallier, C., Devauchelle, A., and Dehaene, S. (2011). Cortical Representation of the Constituent Structure of Sentences. Proc. Natl. Acad. Sci. U.S.A. 108, 2522-2527. doi: 10.1073/pnas.1018711108

Parker, D., and Phillips, C. (2016). Negative polarity illusions and the format of hierarchica encodings in memory. Cognition 157, 321-339. doi: 10.1016/j.cognition.2016.08.016

Parker, D., and Phillips, C. (2017). Reflexive attraction in comprehension is selective. J. Mem. Lang. 94, 272-290. doi: 10.1016/j.jml.2017. 01.002

Pesetsky, D. (1987). "Wh-in-situ: movement and unselective binding," in The Representation of (In)definiteness, eds E. J. Reuland and A. ter Meulen (Cambridge, MA: MIT Press), 98-129.

Phillips, C. (2013). "Parser-grammar relations: we don't understand everything twice," in Language Down the Garden Path: The Cognitive Basis for Linguistic Structure, eds M. Sanz, I. Laka, and M. Tanenhaus (Oxford: Oxford University Press), 294-315. 
Phillips, C., and Lau, E. (2004). Foundational issues. J. Linguist. 40, 571-591. doi: $10.1017 /$ S0022226704002774

Phillips, C., Kazanina, N., and Abada, S. (2005). ERP effects of the processing of syntactic long-distance dependencies. Cogn. Brain Res. 22, 407-428. doi: 10.1016/j.cogbrainres.2004.09.012

Phillips, C., Wagers, M. W., and Lau, E. F. (2011). Grammatical illusions and selective fallibility in real-time language comprehension. Exp. Inter. Syntax Semant. 37, 148-180. doi: 10.1108/S0092-4563(2011)0000037009

Poeppel, D. (2012). The maps problem and the mapping problem: two challenges for a cognitive neuroscience of speech and language. Cogn. Neuropsychol. 29, 34-55. doi: 10.1080/02643294.2012.710600

Poeppel, D., and Embick, D. (2005). "The relation between linguistics and neuroscience," in Twenty-First Century Psycholinguistics: Four Cornerstones. ed A. Cutler (Mahwah, NJ: Lawrence Erlbaum Associates), 103-120.

Poeppel, D., Emmorey, K., Hickok, G., and Pylkkänen, L. (2012). Towards a new neurobiology of language. J. Neurosci. 32, 14125-14131. doi: 10.1523/JNEUROSCI.3244-12.2012

Pylkkänen, L., Brennan, J., and Bemis, D. K. (2011). Grounding the cognitive neuroscience of semantics in linguistic theory. Lang. Cogn. Process. 26, 1317-1337. doi: 10.1080/01690965.2010.527490

Saddy, D., Drenhaus, H., and Frisch, S. (2004). Processing polarity items: contrastive licensing costs. Brain Lang. 90, 495-502. doi: 10.1016/S0093-934X(03)00470-X

Shao, J., and Neville, H. (1998). Analyzing semantic processing using Event-related Potentials. News.Center Res. Lang. 11, 3-20.

Steinhauer, K., Drury, J. E., Portner, P., Walenski, M., and Ullman, M. T. (2010). Syntax, concepts and logic in the temporal dynamics of language comprehension. Neuropsychologia 48, 1525-1542. doi: 10.1016/j.neuropsychologia.2010.01.013

Stowe, L. (1986). Parsing wh-constructions: evidence for on-line gap location. Lang. Cogn. Process. 1, 227-245. doi: 10.1080/01690968608407062

Sturt, P. (2003). The time-course of the application of binding constraints in reference resolution. J. Mem. Lang. 48, 542-562. doi: 10.1016/S0749-596X(02)00536-3

Townsend, D. J., and Bever, T. G. (2001). Sentence Comprehension: The Integration of Habits and Rules. Cambridge, MA: MIT Press.

Tsai, P.-S., Tzeng, O. J.-L., Hung, D. L., and Wu, D. H. (2013). Using magnetoencephalography to investigate processing of negative polarity items in Mandarin Chinese. J. Neuroling. 26, 258-270. doi: 10.1016/j.jneuroling.2012.09.002

Tsai, W.-T. D. (1994). On Economizing the Theory of A-bar dependencies. Ph.D. dissertation, Cambridge; Boston, MA: MIT Press.

Van Berkum, J. J. A., Koornneef, A. W., Ottena, M., and Nieuwland, M. S. (2007). Establishing reference in language comprehension: an electrophysiological perspective. Brain Res. 1146, 158-171. doi: 10.1016/j.brainres.2006.06.091

van Gompel, R. P. G., and Liversedge, S. P. (2003). The influence of morphological information on cataphoric pronoun assignment. J. Exp. Psychol. Learn. Mem. Cogn. 29, 128-139. doi: 10.1037/0278-7393.29.1.128
Vasishth, S., Brüessow, S., Lewis, R. L., and Drenhaus, H. (2008). Processing polarity: how the ungrammatical intrudes on the grammatical. Cogn. Sci. 32, 685-712. doi: 10.1080/03640210802066865

Vespignani, F, Panizza, D., Zandomeneghi, P., and Job, R. (2009). “"Never” in the wrong place: an ERP study of unlicensed NPIs in Italian," in Poster Presented at the 22nd Annual CUNY Conference on Human Sentence Processing (Davis).

Warren, T., and Gibson, E. (2002). The influence of referential processing on sentence complexity. Cognition 85, 79-112. doi: 10.1016/S0010-0277(02)00087-2

Xiang, M., Grove, J., and Giannakidou, A. (2016). Semantic and pragmatic processes in the comprehension of negation: an event related potential study of negative polarity items. J. Neuroling. 38, 71-88. doi: 10.1016/j.jneuroling.2015.11.001

Xiang, M., Dillon, B., and Phillips, C. (2009). Illusory licensing effects across dependency types. Brain Lang. 108, 40-55. doi: 10.1016/j.bandl.2008.10.002

Xiang, M., Dillon, B., Wagers, M., Liu, F. Q., and Guo, T. M. (2013). Processing covert dependencies: an SAT study on Mandarin wh-in-situ questions. J. East Asian Ling. 23, 207-232. doi: 10.1007/s10831-013-9115-1

Xiang, M., Wang, S. P., and Cui, Y. L. (2015). Constructing covert dependencies-the case of wh-in-situ processing. J. Mem. Lang. 84, 139-166. doi: $10.1016 /$ j.jml.2015.05.006

Xu, X., Jiang, X., and Zhou, X. (2013). Processing biological gender and number information during Chinese pronoun resolution: ERP evidence for functional differentiation. Brain Cogn. 81, 223-236. doi: 10.1016/j.bandc.2012.11.002

Yanilmaz, A., and Drury, J. E. (2013). "Processing of negative polarity items in Turkish," in Poster Presented at the Society for the Neurobiology of Language (San Diego, CA).

Yen, H.-L. (2007). Processing of Proper Names in Mandarin Chinese: A Behavioral and Neuroimaging Study. Ph.D. dissertation, Uni Bielefeld.

Yoshida, M., Kazanina, N., Pablos, L., and Sturt, P. (2014). On the origin of islands. Lang. Cogn. Process. 29, 761-770. doi: 10.1080/01690965.2013.788196

Yurchenko, A., den Ouden, D. B., Hoeksema, J., Dragoy, O., Hoeks, J. C. J., and Stowe, L. A. (2013). Processing polarity: ERP evidence for differences between positive and negative polarity. Neuropsychologia 51, 132-141. doi: 10.1016/j.neuropsychologia.2012.10.028

Conflict of Interest Statement: The authors declare that the research was conducted in the absence of any commercial or financial relationships that could be construed as a potential conflict of interest.

The reviewer, EC, and handling Editor declared their shared affiliation.

Copyright (๑) 2018 Pablos, Doetjes and Cheng. This is an open-access article distributed under the terms of the Creative Commons Attribution License (CC BY). The use, distribution or reproduction in other forums is permitted, provided the original author(s) or licensor are credited and that the original publication in this journal is cited, in accordance with accepted academic practice. No use, distribution or reproduction is permitted which does not comply with these terms. 